\title{
Direct and indirect effects of multiple stressors on stream invertebrates across watershed, reach and site scales: a structural equation modelling better informing on hydromorphological
} impacts.

\author{
B. Villeneuve ${ }^{* a}$, J. Piffady ${ }^{a}$, L. Valette ${ }^{a}$, Y. Souchon ${ }^{a}$, P. Usseglio-Polatera ${ }^{b}$ \\ aUR MALY, Irstea Lyon-Villeurbanne, Laboratoire d'hydroécologie quantitative, 5 rue de la Doua, CS20244, 69625 \\ Villeurbanne Cedex, France

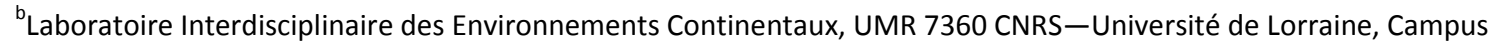 \\ Bridoux, Bât. IBISE, 8 rue du Général Delestraint, 57070 Metz, France \\ *Corresponding author : bertrand.villeneuve@irstea.fr
}

Please cite as : Villeneuve, B., Piffady, J., Valette, L., Souchon, Y., Usseglio-Polatera, P. (2018) Direct and indirect effects of multiple stressors on stream invertebrates across watershed, reach and site scales: a structural equation modelling better informing on hydromorphological impacts. Science of the total environment, 612, 660-671.

\section{Abstract}

The purpose of our approach was to take into account the nested spatial scales driving stream functioning in the description of pressures/ecological status links by analysing the results of a hierarchical model. The development of this model has allowed us to answer the following questions: Does the consideration of the indirect links between anthropogenic pressures and stream ecological status modify the hierarchy of pressure types impacting benthic invertebrates? Do the different nested scales play different roles in the anthropogenic pressures/ecological status relationship? Does this model lead to better understanding of the specific role of hydromorphology in the evaluation of stream ecological status?

To achieve that goal, we used the Partial Least Square (PLS) path modelling method to develop a structural model linking variables describing (i) land use and hydromorphological alterations at the watershed scale, (ii) hydromorphological alterations at the reach scale, (iii) nutrients-organic matter contamination levels at the site scale, and (iv) substrate characteristics at the sampling site scale, to explain variation in values of a macroinvertebrate-based multimetric index: the French $\mathrm{I}_{2} \mathrm{M}_{2}$.

We have highlighted the importance of land use effects exerted on both hydromorphological and chemical characteristics of streams observed at finer scales and their subsequent indirect impact on stream ecological status. Hydromorphological alterations have an effect on the substrate mosaic structure and on the concentrations of nutrients and organic matter at site scale. This result implies that stream hydromorphology can have a major indirect effect on macroinvertebrate assemblages and that the hierarchy of impacts of anthropogenic pressures on stream ecological status generally described in the literature - often determining strategic restoration priorities - has to be reexamined. Finally, the effects of nutrients and organic matter on macroinvertebrate assemblages are lower than expected when all the indirect effects of land use and hydromorphological alterations are taken into account. 


\section{Introduction}

Streams are open systems, and the structure, composition and functioning of the biocenoses they host are closely linked to peri-riverine human activities. In any ecosystems, functional processes interact at multiple spatial and temporal scales (Hynes, 1975; Lévêque, 2001). Streams more or less directly collect the rainfall water within the watershed. Any alteration of the neighbouring terrestrial ecosystems has potential impacts on stream water flow and fluxes of elements - and thus on the downstream aquatic ecosystems - over long distance and at long-term. The linear structure of streams makes autochthonous biotic communities particularly vulnerable to both (i) transversal structures that disrupt water, sediment and biological flows; and (ii) engineered in-stream or riverine structures brought to protect neighbouring areas from extreme meteorological events (Wasson et al., 1993). It has long been recognized that (i) stream functioning is organized according to a hierarchy of spatial scales (Allan, 2004; Frissell et al., 1986; Poff et al., 1997; Roth et al., 1996; Thorp, 2014; Thorp et al., 2006) from the regional scale to the microhabitat scale via the watershed and reach scales, and that (ii) the processes and structures observed at the largest scales (regional, watershed) influence the processes and structures observed at the smallest ones (reach, site). Streams are therefore complex dynamic systems, resulting from continuous adaptations of the liquid and solid compartments in permanent interaction. The geological and geographic contexts coupled with the climatic and hydrological regimes govern stream hydromorphological characteristics (Omernik, 1987). The hydromorphological, hydraulic and thermal characteristics of streams drive the available within-stream physical habitats. Local physical habitats, chemical conditions and the composition and attributes of the potential pool of colonists will determine the local species assemblage, in terms of both composition and structure. In addition to this schematic view, account must be taken of the natural variability of habitats (e.g. inter-annual variations in thermal and hydrological regimes) to which biological communities should be adapted (Piffady et al., 2013).

Moreover, according to the DPSIR concept (Driving forces, Pressures, State, Impact and Response; Kristensen, 2004), human activities (agriculture, urbanization) create driving forces for changes in the abiotic components (physico-chemistry, hydromorphology) of streams via the effects of combined pressures (chemical discharges, physical alterations). These anthropogenic pressures can be ranked hierarchically according to the relative importance of their impact at the different nested spatial scales described by Frissell et al. (1986; from watershed to habitat). Large sectors of intense human activity (e.g. agriculture, urbanization, industries) can have severe impact on the physico-chemical, hydromorphological and hydrological characteristics of streams, via sediment transport alteration, nutrient enrichment, toxic pollution, hydrological modifications, riparian clearing or habitat loss (Allan, 2004; Novotny et al., 2009; Paul and Meyer, 2001). Moreover, flow management for flood prevention, hydroelectricity production and irrigation modify hydraulic regimes, with possible hydromorphological (e.g. disruption in sediment transport continuity, stream bed incision) and thermal (water warming) drawbacks that modify local habitat conditions for biotic communities (Poff et al., 1997; Verdonschot et al., 2016; Villeneuve et al., 2015). The local degradation of stream channel geometry can modify habitats and biogeochemical processes (e.g. disruption of lateral connectivity, loss of connection with neighbouring terrestrial habitats and loss of effective cleaning action; Baker et al., 2012; Weigelhofer et al., 2013). Point and diffuse discharges of toxic substances 
can also impair stream water quality and biotic communities (Archaimbault et al., 2010; Novotny, 2004; Usseglio-Polatera et al., 2001).

The European Water Framework Directive (WFD; European Council, 2000) does not only involve the assessment of the ecological status of water bodies but also the diagnostic of human activity impacts on water bodies. Consequently, it is necessary to provide practical guidelines to aquatic ecosystem managers for facilitating the design of efficient restoration strategies at the scale of coherent management units (e.g. the watershed and reach scales for streams). Although streams are subject to a large variety of significant driving forces and pressures, land use, eutrophication and habitat destruction have been clearly identified as the pressures exhibiting the greatest impacts (Stendera et al. 2012). Changes in land use, hydromorphology and physico-chemistry have already been linked individually to variations in biotic indices based on the taxonomic and/or functional characteristics of assemblages of macrophytes, diatoms, fish and macroinvertebrates (Dahm et al., 2013; Feld, 2013; Marzin et al., 2012; Sponseller et al., 2001; Sundermann et al., 2013; Villeneuve et al., 2015; Wasson et al., 2010). These studies have demonstrated that the links between pressures and biological indices are influenced by the spatial scale at which each pressure is taken into account (Allan, 2004; Allan et al., 1997; King et al., 2005; Lammert and Allan, 1999; Roth et al., 1996). Thus, watershed, hydromorphological reach and riparian corridor are spatial scales that considerably structure the effects of anthropogenic pressures on the ecological status of rivers observed as site scale (see also Marzin et al., 2012; Wasson et al., 2010). Shortly, the previous works have evidenced (i) the significant response of biotic indices to environmental variables characterizing gradients of nutrients, organic matter, hydromorphological pressures and land use at the watershed scale, (ii) the similarity of the core response pattern of all these biotic indices, but (iii) some between-indices differences in responses to specific pressure types, mainly regarding hydromorphology. Nevertheless, most of the time, the factors related to hydromorphological alteration have been ranked only at the third place (in order of decreasing importance of stream ecological status drivers) after physico-chemical and land-use factors. Both Dahm et al. (2013) and Villeneuve et al. (2015) have shown that the effects of hydromorphological pressures on biotic assemblages could be measured, but their impact on the set of tested biological metrics was relatively low. In summary, it seems possible to predict and clearly explain the ecological status of streams on the basis of pressure descriptors. However, the pressure descriptors selected in previous works didn't specifically take into account the multiple nested spatial scales that structure both the anthropogenic pressures and the longitudinal functioning of streams.

The main objective of our study was to explicitly examine the importance of the nested spatial organisation of streams on the links between anthropogenic pressures and stream ecological status, by building - and analysing the results of - a model based on the Partial Least Squares (PLS hereafter) path modelling method (Jakobowicz, 2007; Tenenhaus et al., 2005; Wold, 1982). This method was applied for simultaneously analysing the effects of latent variables (i.e. variables which are not directly observed but supposed to enter into the functioning of the streams under study: e.g. landuse, hydromorphological and physico-chemical pressures) on the ecological status of rivers synthetically measured in this study by the macroinvertebrate-based French biotic index for wadeable rivers $\left[\mathrm{I}_{2} \mathrm{M}_{2}\right.$; (Mondy et al., 2012)], as an example of one of the multimetric indices already in use [see Birk et al. (2012) for a review]. The development of this model should allow us to answer the following questions: 
- How does the consideration of the indirect links between anthropogenic pressures and stream ecological status modify the hierarchy of pressure types impacting benthic invertebrates?

- Do the different nested spatial scales play different roles in the anthropogenic pressures/ecological status relationships?

- Does the new PLS model tested lead to a better understanding of the specific role of hydromorphology in the evaluation of stream ecological status?

\section{Material and methods}

\subsection{Typological classification of sites}

The concept of "ecoregion" was adapted to aquatic ecosystems by Omernik (1987) to define water quality and regionalised management objectives and has been widely used in the USA (Omernik, 2004). The concept of "hydro-ecoregion" (HER), developed in France by Wasson et al. (2002), has been based on a top-down approach whose basic principle for stream classification relies much more on the global control factors (i.e. geology, relief and climate at the watershed scale) rather than their consequences at local level. This concept relies on the hypothesis of a hierarchical organization and control of stream habitat and functioning, in particular at the different nested spatial scales from the watershed to the micro-habitat (Frissell et al., 1986). Wasson et al. (2010) have demonstrated that hydro-ecoregions have the capacity to provide robust typological support for better analysing the causal links between land use and benthic macroinvertebrate assemblages.

For this study, we have chosen to avoid hydro-ecoregions with a too specific hydrological and morphological functioning. Consequently we have discarded the hydro-ecoregions of the mountain and Mediterranean regions, selecting only hydro-ecoregions of lowlands and hills (altitude lower than $450 \mathrm{~m}$ ). More precisely, we have focused the analysis on two groups of hydro-ecoregions distinguished by their geology: 'limestone' vs. 'non-limestone'. Streams of both groups were allocated to two size-based sub-groups to analyse independently small-sized wadeable streams (Strahler ranks from 1 to 3 ) and medium-sized wadeable streams (Strahler ranks from 4 to 6 ).

\subsection{Biological data}

We used information on benthic macroinvertebrate assemblages from a database of 1200 sites of the French monitoring network (RCS) achieved during the 2007-2012 period (Fig. 1).

From this database, it was possible to achieve a sufficient number of sampling events performed in the four groups of sites previously defined ( $\$ 2.1$ ). The first group, representing small non-limestone streams, consisted of 638 sampling events from 160 sites. The second group, representing mediumsized non-limestone streams, included 492 sampling events from 127 sites. The third group, 
representing small limestone streams, was composed of 817 sampling events from 228 sites. The last group, representing medium-sized limestone streams, had 460 sampling events from 128 sites.

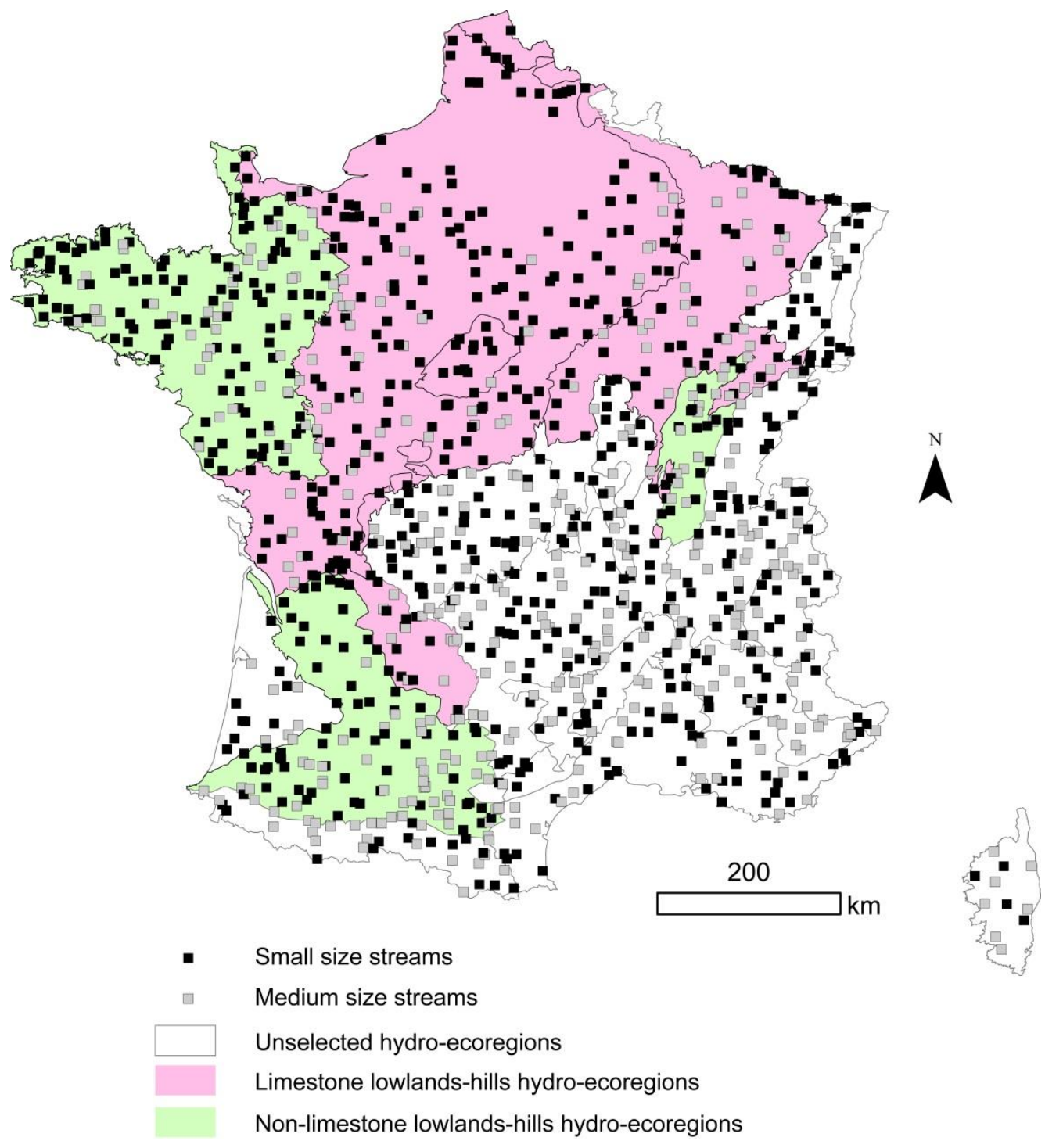

Figure 1. Spatial distribution of the 1200 sites of the French control and monitoring network (RCS) involved in this study.

The benthic macroinvertebrate assemblages were sampled using a common standardized protocol (AFNOR, 2009). The ecological quality of the sites was evaluated with the WFD-compliant biotic index proposed by Mondy et al. (2012) for French wadeable rivers $\left(\mathrm{I}_{2} \mathrm{M}_{2}\right)$. This index takes into account the expected reference conditions for the corresponding river type and integrates several types of pressures through the combination and weighting (by pressure-type specific metric discrimination efficiency) of five taxonomy-based and trait-based metrics: (i) Shannon diversity index, (ii) original Average Score Per Taxon (ASPT), (iii) taxonomic richness, (iv) the relative frequency of polyvoltine organisms, and (v) the relative frequency of ovoviviparous organisms (see Mondy et al., 2012 for further details). These metrics were selected according to their ability to discriminate "impaired" sites from "least impaired" sites (based on 17 physico-chemical and hydromorphological pressure categories), their non-redundancy and their stability under reference conditions. Based on the applied sampling and sorting/identification strategies (AFNOR, 2009 and 2010, respectively), the $\mathrm{I}_{2} \mathrm{M}_{2}$ 
calculation process takes into account the deviation between the observed scores of individual metrics for a tested site and the corresponding river type-specific reference scores. Therefore, the $\mathrm{I}_{2} \mathrm{M}_{2}$ scores are expressed as Ecological Quality Ratios (EQR) with values close to " 1 " being indicative of near reference status and the values close to " 0 " indicating severe deviation from reference conditions.

\subsection{Land use data}

The layer of geographic data used was CORINE Land Cover (CLC) 2006 (Büttner and Kosztra, 2007). It covers the entire territory and is based on a standardized nomenclature ranked according to 44 items distributed in five main types of territorial cover: (i) urban, (ii) agricultural land, (iii) forests and seminatural habitats, (iv) wetlands and (v) bodies of water.

On the basis of the stream catchment delimited beforehand by a digital field model, we calculated for each stream site the relative surface (\%) of four groups of land use categories (Table 1) according to CORINE Land Cover nomenclature: (i) urbanization of the watershed (gathering urban areas, industrial and commercial areas, roads and highways, mines, dumps and construction sites, nonagricultural artificial green spaces), (ii) intensive agriculture (i.e. arable lands, permanent crops, orchards, vineyards, annual crops associated with permanent crops, cropping and field systems), (iii) non-intensive agriculture (i.e. meadows, territories mainly occupied by agriculture with considerable natural vegetation, agro-forestry territories) and non-anthropized spaces (i.e. forests and seminatural habitats, wetlands, ponds).

\subsection{Hydromorphological data}

Two main types of descriptors of the pressures exerted on stream hydromorphological functioning were used: (i) descriptors at the watershed scale and (ii) descriptors at the hydromorphological reach scale (Table 1). At the watershed scale, we used information gathered during the 2000 national agricultural census on drainage, irrigation, erosion and ponds to characterize possible disturbance of both natural sediment and water flows. At the hydromorphological reach scale, we selected several descriptors of the hydromorphological alteration risk including the rate of upstream dams, the rate of stream crossings, the rate of roads in the stream vicinity, the rate of roads in the flood plain, the rate of dikes in the stream vicinity, the rate of dikes in the flood plain, the rate of "wind-break" afforestation on the banks, the rate of riparian forest on the banks, the rate of afforestation in the stream vicinity, the rate of "artificial" land use close to the stream vicinity, the rate of straight channel, the rate of surplus width and the depth/width ratio. These descriptors are generated using information from $\mathrm{BD} \mathrm{TOPO}^{\circledR}$ database (3D vector description of the elements of the territory and of its infrastructures, of metric precision, exploitable on scales ranging from 1: 5000 to 1: 50000). These variables were assessed for each of the selected sites from the database, at the relevant spatial scales (watershed or reach). 
Table 1. Description of pressure variables.

\begin{tabular}{|c|c|c|}
\hline Scale & Variable & $\begin{array}{l}\text { Average values } \\
\text { (min-max range) }\end{array}$ \\
\hline Watershed & $\begin{array}{l}\text { urbanization of catchment: urbanized } \\
\text { zones, industrial and commercial zones, } \\
\text { transport networks, mines, dumps and } \\
\text { construction sites, artificial green spaces, } \\
\text { non agricultural spaces }\end{array}$ & $3.3(0.0-58.7)$ \\
\hline Watershed & $\begin{array}{l}\text { intensive agriculture: arable land, } \\
\text { permanent crops, orchards, vineyards, } \\
\text { olive orchards, annual crops linked to } \\
\text { permanent crops, crop and field systems }\end{array}$ & $35.5(0.0-100.0)$ \\
\hline Watershed & $\begin{array}{l}\text { non-intensive agriculture: meadows, land } \\
\text { mainly devoted to agriculture with } \\
\text { considerable presence of natural } \\
\text { vegetation, agro-forestry land }\end{array}$ & $20.3(0.0-89.9)$ \\
\hline Watershed & $\begin{array}{l}\text { non anthropized space: forests and semi- } \\
\text { natural environments, wetlands, ponds }\end{array}$ & $40.8(0.0-100.0)$ \\
\hline Watershed & Erosion & $0.6(0.0-3.4)$ \\
\hline Watershed & Drainage ratio & $0.03(0.0-1.0)$ \\
\hline Watershed & Irrigation ratio & $0.03(0.00-0.47)$ \\
\hline Watershed & Ponds storage & $0.03(0.00-2.24)$ \\
\hline Reach & Rate of roads/railways near the riverbed & $7.8(0.0-262.0)$ \\
\hline Reach & Rate of roads/railways in the flood plain & $111(0-3087)$ \\
\hline Reach & Rate of dykes in the riverbed & $5(0-393)$ \\
\hline Reach & Rate of dikes in the flood plain & $17(0-764)$ \\
\hline Reach & Rate of stream crossings & $0.8(0.0-8.5)$ \\
\hline Reach & Rate of trees on banks "screen of trees" & $77(0-100)$ \\
\hline Reach & $\begin{array}{l}\text { Rate of vegetation on banks "riparian } \\
\text { vegetation" }\end{array}$ & $59(0-100)$ \\
\hline Reach & Rate of vegetation in riverbed & $48(0-100)$ \\
\hline Reach & $\begin{array}{l}\text { Rate of "artificial" type land use near } \\
\text { riverbed }\end{array}$ & $9.8(0.0-100.0)$ \\
\hline Reach & Rate of straightness & $27.8(0.0-100.0)$ \\
\hline Reach & Rate of ponds in riverbed & $0.7(0.0-33.0)$ \\
\hline Reach & Overwidth & $41.4(0.0-15742.0)$ \\
\hline Reach & Anomaly index of Width/Depth ratio & $3(1-5)$ \\
\hline Site & Suspended matter (mg/L) & $20.5(1.5-1347.0)$ \\
\hline Site & Dissolved oxygen (mg/L) & $10.1(6.1-13.0)$ \\
\hline Site & BOD5 at $20^{\circ} \mathrm{C}(\mathrm{mg} / \mathrm{L})$ & $1.6(0.5-4.7)$ \\
\hline Site & Ammonium (mg/L) & $0.08(0.00-0.47)$ \\
\hline Site & Nitrites (mg/L) & $0.01(0.01-0.98)$ \\
\hline Site & Nitrates (mg/L) & $13.8(0.3-70.4)$ \\
\hline Site & Total Phosphorous (mg/L) & $0.08(0.01-0.48)$ \\
\hline Site & $\begin{array}{l}\text { Substrates mosaic : bryophytes, } \\
\text { hydrophytes, litter, branches and root } \\
\text { mats, pebbles and stones, rocks, gravel, } \\
\text { helophytes, mud, sand and silt, algae and } \\
\text { uniform or artificial area }\end{array}$ & - \\
\hline
\end{tabular}




\subsection{Physico-chemical data}

Informations on the physico-chemical characteristics of sites were obtained from the monthly physico-chemical survey of these sites belonging to the French national monitoring network (RCS). We selected the following parameters: ammonium, nitrites, nitrates, total phosphorous concentrations in water and BOD5 (Table 1). The mean values of these parameters during a one-year period covering the 11 months prior to the date of macroinvertebrate assemblage sampling and the month following this date, were chosen as descriptors of the nutrient and organic matter pressures on site assemblages.

\subsection{Substrate mosaic}

The relative surface (\%) of pre-defined substrate-types within the benthic mosaic of each sampling site was used to describe the local habitat conditions of selected sites. Following the French norm NF T90-333 (AFNOR, 2009), twelve substrate types were considered: (i) bryophytes, (ii) hydrophytes, (iii) litter, (iv) branches and root mats, (v) pebbles and stones, (vi) rocks, (vii) gravel, (viii) helophytes, (ix) mud, $(x)$ sand and silt, (xi) algae and (xii) uniform or artificial areas (Table 1).

\subsection{Modelling method: the PLS approach}

The PLS path modelling method (Wold, 1982) is a statistical method allowing to model complex relationships between observed (= manifest) and latent variables. This method was recently used by Riseng et al. (2011) to develop large scale causal models linking agricultural land use to measured instream conditions. This type of model belongs to the structural equation models (SEM) (Bizzi et al., 2013; Grace et al., 2010) which encompass a large number of statistical methods used to estimate complex causal relationships between latent and manifest variables. In recent years, this approach has become increasingly popular in various scientific communities including econometrics and social sciences (Vinzi et al., 2010).

A structural PLS model is described by two sub-models: (1) the measurement model (or external model) linking the manifest variables to the corresponding latent variables, and (2) the structural model (or internal model) taking into account the relationships among the latent variables (Vinzi et al., 2010).

We first estimated the latent variables with the external model (Tenenhaus et al., 2005). The external estimation $Y_{j}$ of the latent variable $\xi_{j}$ was built as a linear combination of the manifest variables $x_{j h}$ : $Y_{j}=\sum_{h} w_{j h} x_{j h}$

where $w_{j}$ was the column vector of the coefficients $w_{j h}$. Variable $Y_{j}$ was forced by standardization. 
Then the internal estimation $Z_{j}$ of the latent variables was performed using external estimations $Y_{i}$ of latent variables $\xi_{\mathrm{i}}$ linked to $\xi_{\mathrm{j}}$ :

$Z_{j} \propto \sum_{i} e_{j i} Y_{i}$

where the $\propto$ sign means that the variable positioned on the left of this sign is obtained by reducing the variable positioned on the right.

These two steps were repeated until reaching convergence. Then we estimated the coefficients $\mathrm{e}_{\mathrm{ji}}$ of the model, called path coefficients, by PLS regressions. The hypothesis of nullity of these coefficients $\left(H_{0}\right)$ was then tested using the bootstrap method for resampling. All the coefficients presented in this work were significant.

The main advantage of this method lays in its capacity to evaluate the direct and indirect effects of a latent variable " $A$ " on another latent variable " $\mathrm{B}$ " (Sanchez, 2013). The direct effect is given by the path coefficient between the two variables $A$ and $B$. The indirect effect, which corresponds to the potential influence of $A$ on $B$ via a third variable " $C$ ", is calculated as the product of the path coefficients between $A$ and $C$ and between $C$ and $B$, respectively. Finally, the total effect of a latent variable $A$ on a latent variable $B$ corresponds to the sum of these direct and indirect effects. For an easier interpretation of the structural model, the direct and total effects were calculated and converted into percentages to better represent the contribution of the latent variables to the variance explained by the model and rounded to avoid decimals. The details of the algorithm developed by Wold (1982) are available in Tenenhaus et al. (2005) or Jakobowicz (2007).

The structural model was evaluated on the basis of the predictive pertinence of the latent variables. For this purpose, it is advisable to analyse the multiple $R^{2}$. According to Croutsche (2002), three thresholds of multiple $\mathrm{R}^{2}$ can be taken into account. The model can be considered as significant if $\mathrm{R}^{2}$ is higher than $10 \%$; tangent if $R^{2}$ is between $5 \%$ and $10 \%$, and not significant if $R^{2}$ is lower than $5 \%$. Multiple $R^{2}$ have been rounded to avoid decimals.

Lastly, each structural equation was evaluated by the Stone-Geisser's coefficient $Q^{2}$, also called crossvalidated redundancy index by Tenenhaus et al. (2005). It includes a cross-validated $R^{2}$ test between the manifest variables of an endogenous latent variable and all the manifest variables associated with the latent variables explaining the endogenous latent variable, using the structural model estimated. If the $Q^{2}$ value is positive, the model exhibits predictive validity. If the $Q^{2}$ value is negative, the model has no predictive validity (Tenenhaus et al., 2005).

Applying this methodology, we have developed a structural model (Fig. 2) linking the latent variables of: (i) land use, hydromorphological alterations at watershed scale, (ii) hydromorphological alterations at reach scale, (iii) concentrations of nutrients and organic matter, and substrate mosaic composition at site scale, with the objective to explain variations in the $I_{2} M_{2}$ macroinvertebratebased index, for the four selected stream types. 


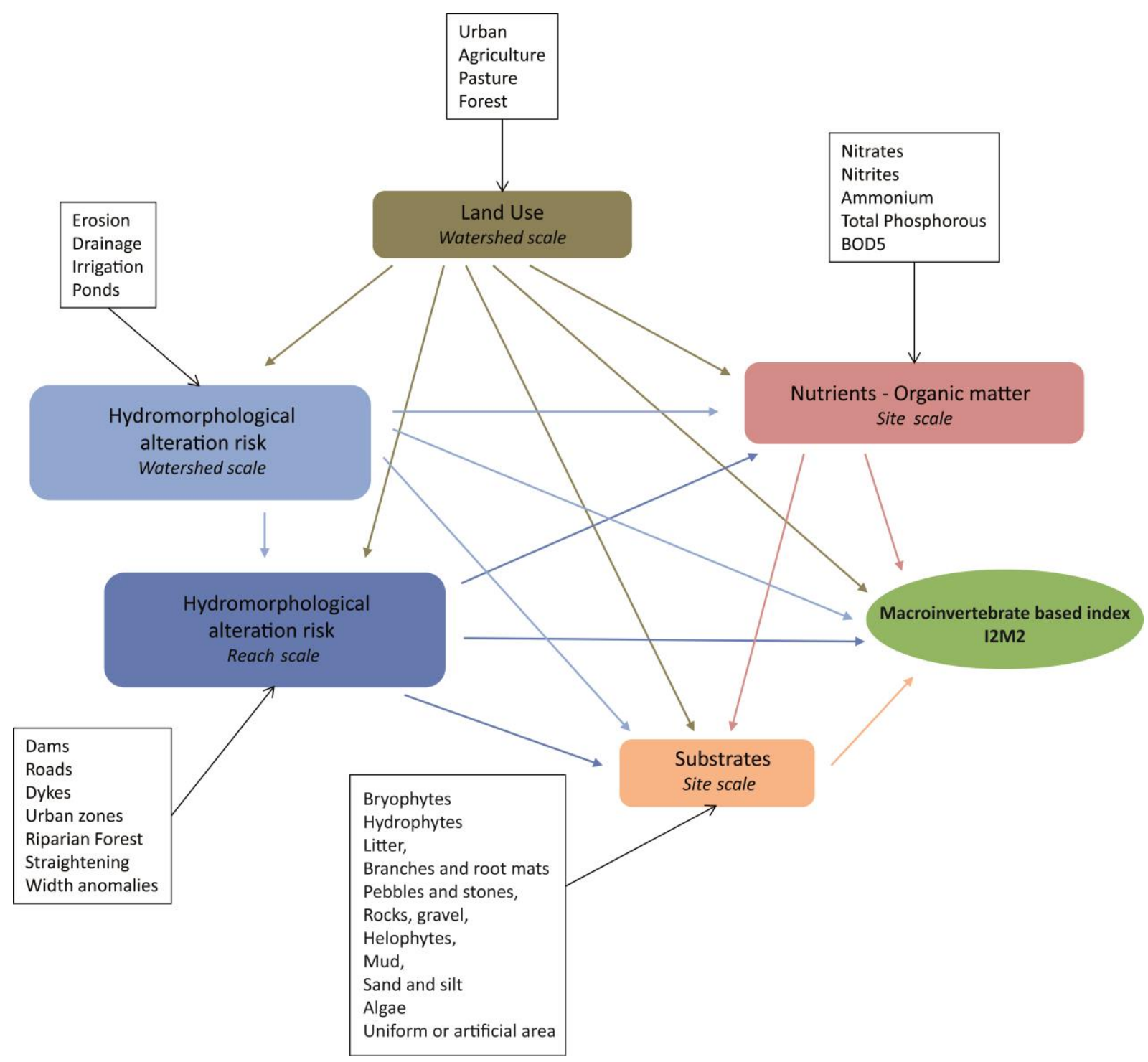

Figure 2: Design of the multiscale and multi-stressors structural model. Each latent variable is represented by a coloured box and each direct effect from this latent variable to another is represented by an arrow of the same colour. Each latent variable is a linear combination of the manifest variables listed in the black frame associated using a black arrow.

\section{Results}

\subsection{Analysis and validation of the structural models}

Analysing the validation index values for the structural model showed that this model is able to satisfactorily explain and predict the $\mathrm{I}_{2} \mathrm{M}_{2}$ values for the four selected stream types (Table 2) with a $\mathrm{R}^{2}$ of $33 \%$ for the non-limestone small streams, $50 \%$ for the non-limestone medium streams, $44 \%$ for the limestone small streams and $40 \%$ for the limestone medium streams. All the $Q^{2}$ values being positive for the $I_{2} M_{2}$ (Table 2 ), the four models have shown good capacity of $I_{2} M_{2}$ prediction. 
The hydromorphological alterations at the watershed scale were very poorly explained by land use at the same scale ( $R^{2}$ varying from $1 \%$ to $4 \%$; Fig. 3 ). The hydromorphological alterations at the reach scale were also rather poorly explained by land use and hydromorphological alterations at the watershed scale ( $R^{2}$ from 10 to $19 \%$; Fig. 3). At reach scale, most of the information was provided by land use (48-93\% of the $R^{2}$ values; Fig. 3$)$, underlining that the hydromorphological alteration risks at watershed and reach scales do not indicate the same processes.

The concentrations in nutrients and organic matter at the site scale were fairly explained by land use at the watershed scale and the risk of hydromorphological alterations both at the watershed and reach scales ( $R^{2}$ varying from 27 to $57 \%$, with always positive $Q^{2}$ values; Fig. 3 ).

The substrate mosaic of sampled sites was more or less successfully explained according to river types ( $R^{2}$ varying from 10 to $51 \%$; Fig. 3 ). It was better explained for medium-sized streams $(51 \%$ and $28 \%$ for 'non limestone' and 'limestone' streams, respectively) than for small-sized streams ( $10 \%$ and $15 \%$, respectively). The $Q^{2}$ values were positive only for medium-sized streams.

Table 2. Validation indices of the structural model : multiple $R$ squared $\left(R^{2}\right)$ and Stone-Geisser's coefficient $\left(Q^{2}\right) . R^{2}$ is the contribution to the variation in $I_{2} M_{2}$ values explained by the model. The model can be considered as significant if $R^{2}$ is higher than $10 \%$; tangent if $R^{2}$ is between $5 \%$ and $10 \%$, and not significant if $R^{2}$ is lower than $5 \% . Q^{2}$ assess the model validity (If the $Q^{2}$ value is positive, the model exhibits predictive validity, if the $Q^{2}$ value is negative, the model has no predictive validity).

\begin{tabular}{lcccccccc}
\hline & $\begin{array}{c}\text { Non } \\
\text { limestome } \\
\text { small streams }\end{array}$ & $\begin{array}{c}\text { Non limestone } \\
\text { medium } \\
\text { streams }\end{array}$ & $\begin{array}{c}\text { Limestome } \\
\text { small streams }\end{array}$ & $\begin{array}{c}\text { Limestone } \\
\text { medium } \\
\text { streams }\end{array}$ \\
\hline $\begin{array}{l}\text { Watershed hydromorphological } \\
\text { alteration risk }\end{array}$ & $2 \%$ & -0.14 & $4 \%$ & -0.11 & $1 \%$ & -0.16 & $1 \%$ & -0.09 \\
$\begin{array}{l}\text { Reach hydromorphological } \\
\text { alteration risk }\end{array}$ & $10 \%$ & -0.07 & $13 \%$ & -0.05 & $19 \%$ & -0.01 & $11 \%$ & -0.05 \\
$\begin{array}{l}\text { Nutrients and organic matter } \\
\text { Substrate mosaic }\end{array}$ & $27 \%$ & 0.08 & $57 \%$ & 0.36 & $42 \%$ & 0.13 & $40 \%$ & 0.15 \\
$\mathrm{I}_{2} \mathrm{M}_{2}$ biotic index & $10 \%$ & -0.04 & $51 \%$ & 0.07 & $15 \%$ & -0.03 & $28 \%$ & 0.02 \\
\hline & $33 \%$ & 0.24 & $50 \%$ & 0.50 & $44 \%$ & 0.32 & $40 \%$ & 0.34 \\
\hline
\end{tabular}


A. Non limestone small streams
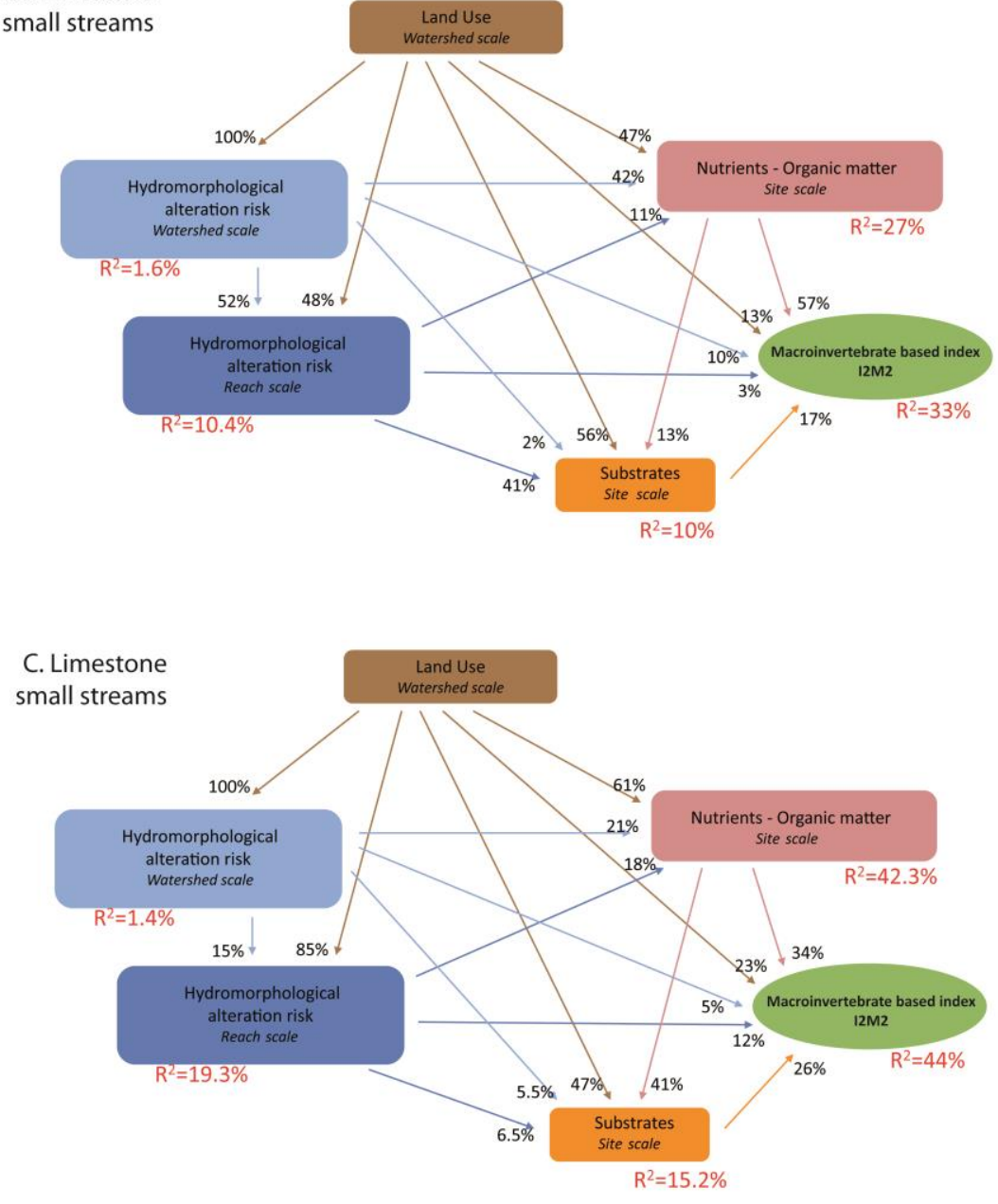
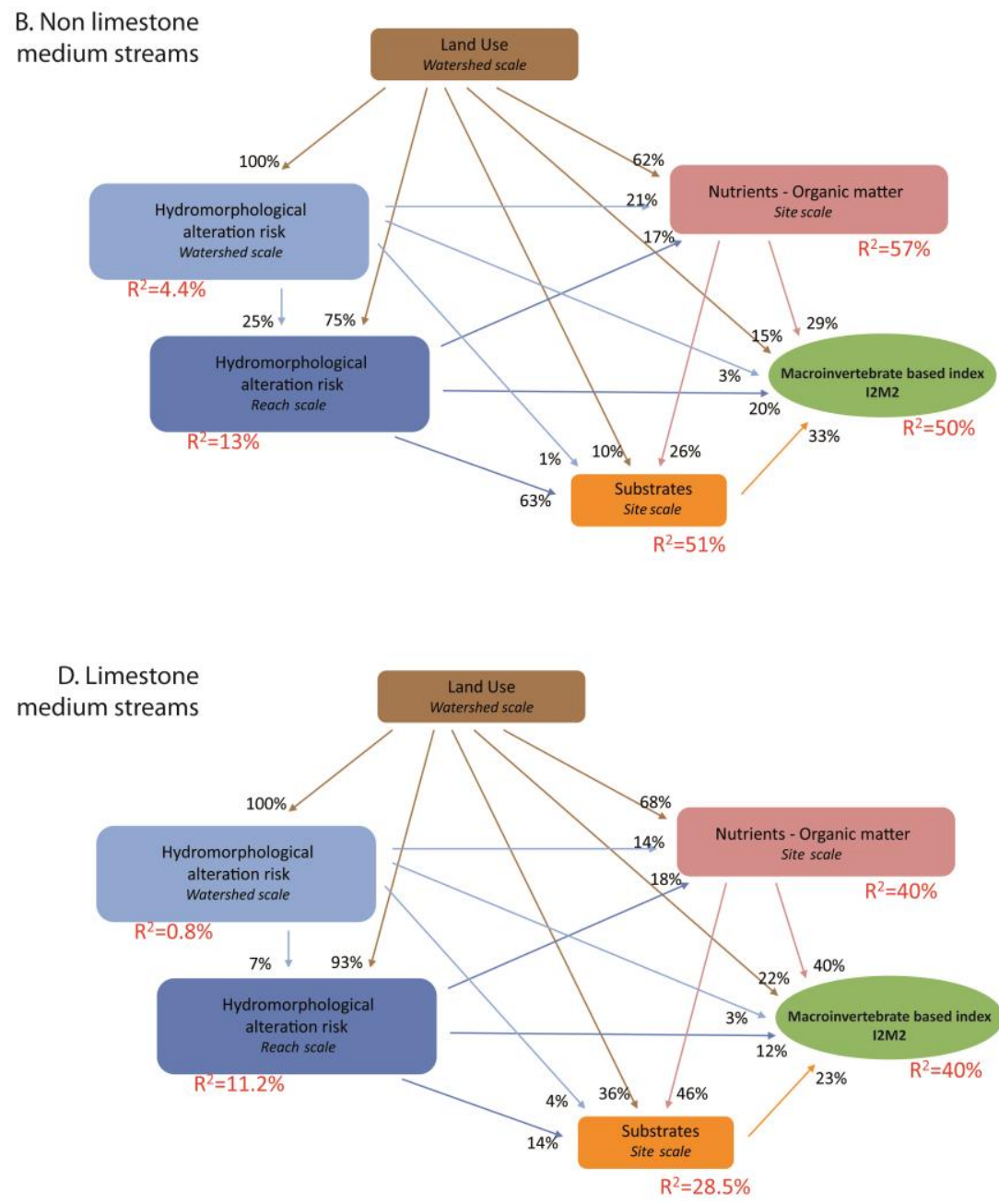

Figure 3. Models derived from PLS path modelling for non limestone small streams (A), non limestone medium streams (B), limestone small streams (C) and limestone medium streams (C). Each latent variable is represented by a coloured box and each direct effect from this latent variable to another is represented by an arrow of the same colour. R2 of each internal model are represented in red. Contributions of latent variables to the variation in $\mathrm{I}_{2} \mathrm{M}_{2}$ values explained by a model (in percentages of the model R2) are represented in black. 


\subsection{Direct effects}

The latent variables with the greatest effects on the $\mathrm{I}_{2} \mathrm{M}_{2}$ values were most often the concentrations of nutrients and organic matter. However the response pattern differed according to stream type (Fig. 3). For non-limestone small streams, the order of decreasing contribution to the variation in $\mathrm{I}_{2} \mathrm{M}_{2}$ values explained by the model was: nutrients and organic matter $(57 \%)$, substrate mosaic $(17 \%)$, watershed land use (13\%), hydromorphological alterations at the watershed $(10 \%)$ and reach (3\%) scales. For non-limestone medium-sized streams, this order was different: substrate mosaic (33\%), nutrients and organic matter (29\%), hydromorphological alterations at the reach scale $(20 \%)$, watershed land use (15\%) and hydromorphological alterations at the watershed scale (3\%). For limestone small- and medium-sized streams, the order of decreasing contribution to $\mathrm{I}_{2} \mathrm{M}_{2}$ value variation was similar: nutrients and organic matter (34\% and $40 \%$, respectively), substrate mosaic ( $26 \%$ and $23 \%)$, watershed land use (23\% and $22 \%)$, hydromorphological alterations at the reach (12\% and $12 \%)$ and watershed (5\% and $3 \%)$ scales.

\subsection{Total effects (direct + indirect)}

When focusing on the total effects (direct + indirect) of latent variables on the $I_{2} M_{2}$ values, although the variables with the major impact remained the concentrations in nutrients and organic matter for non-limestone small streams, the relative contributions of indirect effects considerably modified the hierarchical order of impacts of the other latent variables for the other stream types (Fig. 4). Indeed, for non-limestone small streams, the order of decreasing contribution to the variation in $\mathrm{I}_{2} \mathrm{M}_{2}$ values explained by the model was: nutrients and organic matter (42\%), watershed land use (21\%), hydromorphological alterations at the watershed scale (16\%), substrate mosaic (15\%) and hydromorphological alterations at the reach scale (6\%). In contrast, in non-limestone medium-sized streams, the decreasing impact importance order was modified in: watershed land use (29\%), hydromorphological alterations at the reach scale $(29 \%)$, nutrients and organic matter (18\%), substrate mosaic (17\%) and hydromorphological alterations at the watershed scale (7\%). For limestone small streams, this order was: watershed land use (33\%), substrate mosaic $(25.0 \%)$, nutrients and organic matter (19\%), hydromorphological alterations at the reach (15\%), and watershed (8\%) scales. For limestone medium-sized streams, it was: watershed land use (35\%), nutrients and organic matter (24\%), substrate mosaic (18\%), hydromorphological alterations at the reach $(18 \%)$ and watershed $(5 \%)$ scales.

\subsection{Synthesis of the effects by spatial scale}

Another potential way to consider the contributions of latent variables was to sum them by homogeneous level of spatial scale (Fig. 5). Land use and hydromorphological alterations at the watershed scale represented the watershed level. Hydromorphological alterations at the reach scale represented an intermediate spatial level covering pressures at the scale of the sub-watershed or the 
hydromorphological reach. Substrate mosaic composition and concentrations in nutrients and organic matter represented explicative parameters observed directly at the site level.

When adding the direct contributions of the latent variables to the $R^{2}$ by level of scale, the site level exhibited the highest contribution to the variation in $\mathrm{I}_{2} \mathrm{M}_{2}$ values explained by the model (from $60 \%$ to $74 \%$ of the direct effect contribution to $\mathrm{I}_{2} \mathrm{M}_{2}$ variation). The remaining contribution was shared between the reach scale (from $3 \%$ to $20 \%$ of the $\mathrm{R}^{2}$ ) and the watershed scale (from $18 \%$ to $28 \%$ of the $R^{2}$ ), thus exhibiting a greater contribution of the watershed scale to $I_{2} M_{2}$ variation.

When grouping the direct and indirect effects (= total effects), the watershed and reach scale effects on the biotic index values increased considerably, representing up to $65 \%$ of the total explained variance (42-65\% according to stream types).

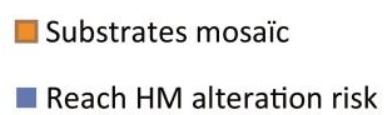

Land Use

$$
\begin{aligned}
& \text { Nutrients and organic matter } \\
& \text { Watershed HM alteration risk }
\end{aligned}
$$

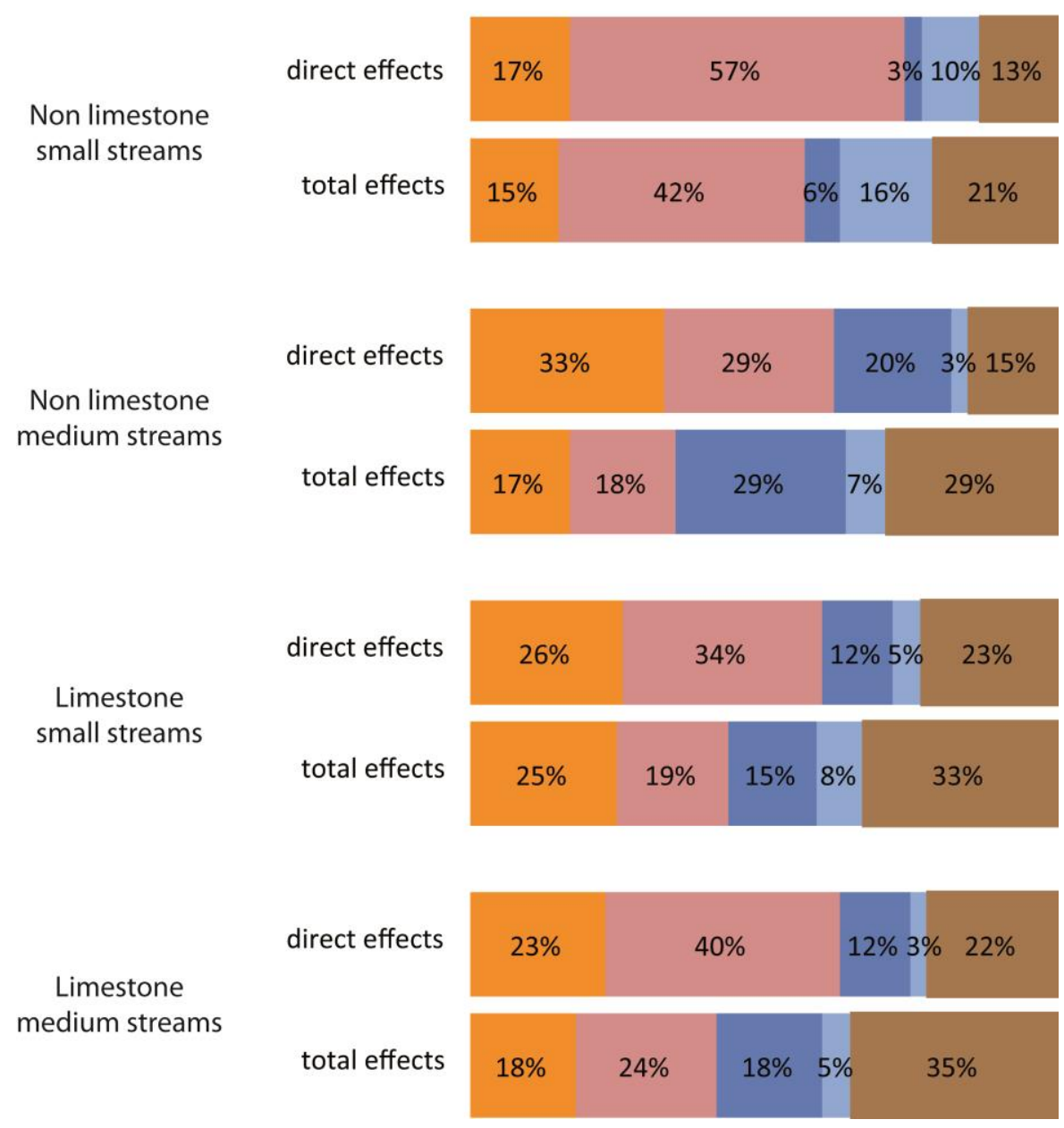

Figure 4. Relative contribution of latent variables to the variation in $\mathrm{I}_{2} \mathrm{M}_{2}$ values explained by the model taking into account direct effects only or total effects (directs + indirects) for the four stream types. 


\subsection{Focusing on the effects of hydromorphology}

Lastly, the total of the direct contributions of the hydromorphological variables, both at the watershed and reach scales, represented from $13 \%$ to $23 \%$ of the total variance in the $I_{2} \mathrm{M}_{2}$ values explained by the models (Fig. 4). These contributions increased from $6 \%$ (small-sized streams) to $13 \%$ (non-limestone medium-sized streams) when taking into account also the indirect effects of watershed and reach hydromorphology on the physico-chemical and habitat mosaic characteristics of sites, providing total contributions from $22 \%$ to $36 \%$ (depending on stream types) of the explained variance in $\mathrm{I}_{2} \mathrm{M}_{2}$ values.

\section{Non limestone small streams} Non limestone
medium streams

$\begin{array}{cc}\text { Limestone } & \text { direct effects } \\ \text { small streams } & \text { total effects }\end{array}$

$$
\begin{aligned}
& \text { direct effects } \\
& \text { total effects }
\end{aligned}
$$

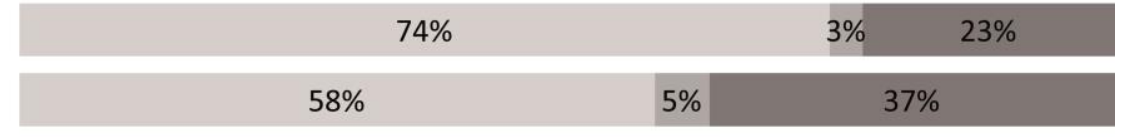

\begin{tabular}{|c|c|c|c|}
\hline \multicolumn{2}{|c|}{$60 \%$} & $12 \%$ & $28 \%$ \\
\hline $44 \%$ & $15 \%$ & & \\
\hline
\end{tabular}

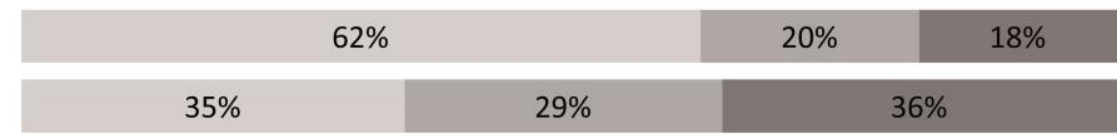

\begin{tabular}{|c|c|c|c|}
\hline \multicolumn{2}{|c|}{$63 \%$} & $12 \%$ & $25 \%$ \\
\hline $42 \%$ & $18 \%$ & & $40 \%$ \\
\hline
\end{tabular}

Figure 5. Relative contribution of scales levels to the variation in $\mathrm{I}_{2} \mathrm{M}_{2}$ values explained by the model taking into account direct effects only or total effects (directs + indirects) for the four stream types. 


\section{Discussion}

The hierarchy of pressure categories can differ according to the type of stream studied. In hard water streams (i.e. limestone streams), hydromorphology and land use had a considerable impact on macroinvertebrate assemblages, sometimes greater than that of water physico-chemistry. In contrast, in soft-water small streams (i.e. non-limestone streams), physico-chemical parameters were the major drivers of the structure and composition of invertebrate assemblages, and then of the invertebrate-based biotic index variations. Hard-water habitats are naturally more productive than soft-water ones (Hill and Webster, 1982; Hill, 1992; Jin and Ward, 2007). Under natural conditions, low primary production limits the secondary production (Cross et al., 2006). The benthic invertebrate habitat conditions will be less buffered and more vulnerable to imbalance during physico-chemical stress in soft habitats. However, in hard-water habitats, since primary production is naturally higher, the secondary production would therefore be more stable and more effectively buffered when a physico-chemical stress occurs. Finally, stream ecological and geomorphic responses to anthropogenic pressures should be calibrated to the regional hydroclimatic, geological, and historical contexts in which the stream occurs, to determine the degree to which the responses of stream invertebrate assemblages to anthropogenic pressures are region-specific or region-independent and broadly transferable (Poff et al., 2006).

When considering only the direct effects of pressures, the variables acting at site scale were the major drivers of variation in stream ecological status. But when considering both the direct and indirect effects of anthropogenic pressures, the contributions of the variables acting at the watershed and reach scales greatly increased and became dominant, as predicted by most of the papers dealing with the hierarchical ordination of factors determining the ecological functioning of streams (e.g. Allan, 2004; Frissell et al., 1986; Poff et al., 1997; Roth et al., 1996; Thorp, 2014; Thorp et al., 2006, Wasson et al., 2002). At the watershed scale, the factors determining stream ecological functioning are depending on the "primary determinants" of geology (e.g. the nature of rocks), relief (geomophology) and climate (temperatures and precipitations)(Frissel et al., 1986). Soils and vegetation within the watershed are components of the flow of water and sediment dynamics, although they are determined by geophysical and climatic characteristics. These factors influence processes at the reach scale, where abiotic factors of control drive the fluvial morpho-dynamics (e.g. bed shape and stability), the structure of the riverine vegetation (which significantly influences aquatic habitat conditions) and the stream connectivity (e.g. stream interactions with the floodable zone)(Montgomery \& MacDonald 2002). Finally, at local scale, the biodiversity and productivity of benthic communities respond to key factors related to the physical habitat (hydraulics, substrate), the aquatic climate (light, temperature, dissolved gases, hydrochemistry) and the trophic resources (autochthonous primary production and exogenous organic matter)(Robinson et al. 2002). Moreover, the influence of habitat characteristics on major parameters like oxygenation and trophic resources led to assigning a preponderant role to the physical factors supporting in-stream biotic conditions.

Many studies examining the responses of biotic assemblages to various stressors acting at different spatial scales, have often shown a preponderant impact of physico-chemical parameters measured at the site scale (e.g. nutrients and organic matter). This major effect was followed, in order of decreasing importance of biotic impact, by land use at the watershed scale, and then by hydromorphological alteration factors, whose effects are much more difficult to evidence (Dahm et 
al., 2013; Villeneuve et al., 2015). For example, Hering et al. (2006) have shown that assemblages of macroinvertebrates, diatoms, macrophytes and fish responded less strongly to land use gradient than to nutrient enrichment. However, their study did not take into account the indirect effects of land use. In addition, they have highlighted the potential alteration of biotic communities through numerous cause-effect relationships acting individually or in concert, including the effects of sedimentation and hydromorphological alteration, diffuse contaminations as well as direct inputs of toxic substances (metals, pesticides). Our results were consistent with these previous works that had shown the preponderant effect of water physico-chemistry - but also bottom substrate composition - on biotic assemblages at the site scale.

However, considering the indirect effects of land use has shown clearly that, except for nonlimestone small streams, the global effect of land use on invertebrate assemblages could be more important than the global effect of nutrients and organic matter (cf. Fig. 4). Different human activities (urbanization, agriculture, industry, transport, etc.) generate strong pressures on the aquatic environments. These pressures can be expressed at the local and reach scales by metrics measuring physico-chemical and hydromorphological alterations, respectively. At the watershed scale, land use descriptors have also the potential to highlight the presence of stressor sources potentially altering the ecological status of rivers at the site scale (Allan, 2004). Indeed, several works have already demonstrated that land use has an effect on macroinvertebrate assemblages at multiple scales (Wang and Kanehl, 2003; Wang et al., 2007; Weigel et al., 2003). Consequently, whatever the scale of measurement applied to abiotic variables (watershed, reach or site), we can consider that the direct effects best measure the impact of individual variables at the site scale whereas the indirect effects best measure the impact of individual variables at larger scales.

Both urban and agricultural areas have a major direct impact on biotic assemblages, as highlighted by many authors (Allan, 2004; Clapcott et al., 2012; Dahm et al., 2013; Marzin et al., 2012; Marzin et al., 2013). Such link appears quite more clearly in the analysis of our model results due to the clear separation of direct from indirect effects, something that had not been done before. The presence of a heavily anthropized upstream catchment can have three types of impact on streams (Allan, 2004; Effenberger et al., 2006; Paul and Meyer, 2001; Stepenuck et al., 2002): it increases (i) runoff and thus erosion and diffuse pollution; (ii) chemical contamination; and (iii) the alteration of stream hydromorphological functioning (e.g. via riparian vegetation eradication, water course straightening and re-gauging, and stream bottom incision). As a result, land use can be an efficient indirect descriptor of the pressures exerted on a stream, at the different functional scales structuring this aquatic ecosystem (Allan, 2004). We have found similar results with our models with significant contributions of land use on the characteristics of the hydromorphological reach, the water physicochemistry and the composition of the site substrates mosaic. Furthermore, when measuring the direct effects of land use at the site scale, we omitted all the indirect processes (e.g. the potential increase in $\mathrm{N}$ and $\mathrm{P}$ concentrations or in the clogging risk) that govern these effects.

The main objective of selecting hydromorphological alteration descriptors was to take into account explicitly alterations of non-natural origin that could be clearly correlated with the degradation of stream ecological status. This strategy has allowed us to consider different stream watershed (agriculture, urbanization, transport) and stream channel (transport, energy, tourism) uses, resulting in potential alterations of in-stream structures and hydromorphological processes. The observed responses of benthic macroinvertebrates to changes in hydromorphology (reach scale) support the results of a lot of previous studies (Buffagni et al., 2004; Hering et al., 2004; Lorenz et al., 2004). 
However, in most of the previous studies (e.g. Dahm et al., 2013; Hering et al., 2006; Villeneuve et al., 2015), the biotic impact of hydromorphological alterations was considered as less important than that of physico-chemical parameters and land use with the conclusion that if the effects of hydromorphological pressures could be measured, their impact was relatively weak on biological metrics. Two aspects of our modelling design have advocated for re-evaluating the impact of hydromorphological pressures on stream macroinvertebrate assemblages: (i) the explicit taking into account of two levels of spatial scale (watershed and reach) and (ii) the analysis of indirect effects of hydromorphological alteration on physico-chemical characteristics and habitat mosaic attributes of sites. Indeed, the total contribution of hydromorphological descriptors - at both watershed and reach scales - to invertebrate-based biotic index variation corresponded to about the same amount of impact as land use, when considering either direct or indirect effects (Fig. 4). Enhancing the description of hydromorphological pressures has provided a better appraisal of the link between hydromorphology and stream biological status. Obviously, the alteration of hydromorphological processes at the reach scale directly acts on macroinvertebrate assemblages by degrading their benthic habitats. The presence of weirs or dikes, the alteration of banks, the degradation of the riparian vegetation and of the bed geometry can lead, in particular, to the modification of the instream facies which become more lentic, thereby directly modifying the available benthic substrate mosaic. Previous studies have already addressed the role of spatial scales in hydromorphological alterations-community relationships (Dahm et al., 2013; Feld and Hering, 2007; Hering et al., 2006; Lamouroux et al., 2004). In consistency with our results, they have highlighted the important role of processes acting at the reach scale in these relationships. Our analysis has reinforced the robustness of such results because based on a larger data set of 643 sites and more than 2,400 sampling events. Taking into account the alterations linked to erosion of agricultural surfaces, irrigation, drainage and water storage at large spatial scale allows the inclusion of processes acting at the watershed scale even if such processes can also act directly on biotic assemblages at the reach and site scales. The direct effects of these variables could be evidenced by an increase in suspended (and deposited) fine sediments and clogging risk, and more severe droughts. Moreover, we have demonstrated that stream hydromorphology has a direct effect on nutrient and organic matter flows. A modification of the morphological facies can potentially modify the residence time of molecules, the infiltration rate in the downwelling areas, the self-purification capacity of streams and other internal physicochemical processes depending on hydromorphological conditions (Baker et al., 2012). Consequently, taking into account these indirect effects via the concentrations of nutrients and organic matter can enhance the explained proportion of the total effect of hydromorphology (at watershed and reach scales) on macroinvertebrate assemblage structure and functions.

Riseng et al. (2011) highlighted the ability of structural equations modelling to build conceptual causal models (i.e. models that represent the hypothesized causal linkages among variables in the system to analyze). The PLS Path modelling method, which belongs to the structural equation modelling (SEM) family, has allowed us (i) to develop a model taking into account the hierarchical spatial organization of streams by considering three scales (watershed, reach and site) and (ii) to evaluate both the direct and indirect effects of several categories of pressures on stream macroinvertebrate assemblages. Understanding the effects of multiple stressors - acting as multiple spatial scales - is not straightforward, in particular if strong stressor interactions are supposed to influence the responses of biological or ecological characteristics of biotic assemblages (Feld et al., 2016). Today, managers urgently need tools that can support them in the decision making process for protecting and restoring river ecosystems, either for biodiversity conservation or restoration 
issues. The major interests of the holistic approach developed in this work are, in particular, to identify (i) the large upstream landscape structures generating the pressures significantly acting on stream ecological status at the site scale and (ii) the most suitable management scale for preserving or restoring a given site (Forbes et al 2008, Thoms et al., Van Looy et al., 2015, Vorosmarty et al., 2010). However, our approach does not describe the whole chain of causality ranging from large scale structures and human activities to natural local process alterations, potentially acting at the different scales of functioning of river ecosystems. Clearly understanding this chain of causality is an extremely ambitious challenge. However, current knowledge does not allow to quantify precisely all the mechanisms involved in such processes (Downes 2010, Norris et al., 2012). Many mechanisms are still unknown, or difficult to characterize due to the lack of data (e.g. disruption in sediment transport continuity or stream bed incision). But we are now able to provide two major pieces of information to managers based on solid evidence. First, the restoration or conservation actions conducted at the watershed or reach scales can have significant effects on stream ecological status at the site scale. Second, hydromorphological alterations play an important role in the relationship between nutrient/organic matter flows and stream ecological status.

\section{Conclusions}

The aim of this study was to address three specific points: the indirect effects of anthropogenic pressures on stream ecological status, the individual importance of processes at three nested spatial scales (watershed, reach and site) on stream ecological status, and the specific role of hydromorphology in pressures-impacts relationships.

First, taking into account the indirect structuring effects of anthropogenic pressures for explaining variations in the French invertebrate-based biotic index has made possible to revise the hierarchy of pressure-type impacts. Indeed, when focusing on the total (direct + indirect) effects of latent variables on the $\mathrm{I}_{2} \mathrm{M}_{2}$ values, the contribution of indirect effects can deeply modify the hierarchy of impacts of the different latent variables (except for small non-limestone streams). More precisely, the total contribution of land use and hydromorphological alteration risk to the biotic index value variations increases while the contribution of physico-chemical parameters (nutrient and organic matter concentrations) decreases.

Second, we have highlighted the importance of the site scale (physico-chemical variables and benthic substrate mosaic descriptors) in explaining stream biological condition. We have demonstrated also the important role of variables measured at the reach scale, both directly via their effects on local habitat features, and indirectly via their confounding effects on the relationship between water physico-chemistry and macroinvertebrate assemblage structure and composition (integrated by the biotic index). Lastly, we have shown that the variables measured at the watershed scale (i.e. land use and large scale hydromorphological characteristics) integrate all the types of upstream pressures acting at finer scales and play a strong structural role on the stream invertebrate assemblages through their indirect effects on all the pressure types.

Third, we have shown the indirect role of hydromorphology on the relationships between other pressures and stream ecological status. These relationships require further study to more precisely 
identify the involved underlying processes, which are of particular interest for optimizing decision making on future physical restorations of streams.

\section{References}

AFNOR. Qualité de l'eau - Prélèvement des macro-invertébrés aquatiques en rivières peu profondes. XP T90-333. Association française de normalisation 2009.

AFNOR. Qualité de l'eau - Traitement au laboratoire d'échantillons contenant des macro-invertébrés de cours d'eau. XP T90-388, Association française de normalisation 2010.

Allan JD. Influence of land use and landscape setting on the ecological status of rivers. Limnetica 2004; 23: 187-196.

Allan JD, Erickson DL, Fay J. The influence of catchment land use on stream integrity across multiple spatial scales. Freshwater Biology 1997; 37: 149-161.

Allan JD, Johnson LB. Catchment-scale analysis of aquatic ecosystems. Freshwater Biology 1997; 37: 107-111.

Archaimbault V, Usseglio Polatera P, Garric J, Wasson JG, Babut M. Assessing toxic sediment pollution in streams using bio-ecological traits of benthic macroinvertebrates. Freshwater Biology 2010; 55: 1430-1446.

Baker DW, Bledsoe BP, Price JM. Stream nitrate uptake and transient storage over a gradient of geomorphic complexity, north-central Colorado, USA. Hydrological Processes 2012; 26: 32413252.

Birk S, Bonne W, Borja A, Brucet S, Courrat A, Poikane S, et al. Three hundred ways to assess Europe's surface waters: an almost complete overview of biological methods to implement the Water Framework Directive. Ecological Indicators 2012; 18: 31-41.

Bizzi S, Surridge BWJ, Lerner DN. Structural equation modelling: a novel statistical framework for exploring the spatial distribution of benthic macroinvertebrates in riverine ecosystems. River Research and Applications 2013; 29: 743-759.

Borchardt $\mathrm{D}$, Richter $\mathrm{S}$. Identification of significant pressures and impacts upon receiving waters. Water Science and Technology 2003; 48: 33-38.

Buffagni A, Erba S, Cazzola M, Kemp JL. The AQEM multimetric system for the southern Italian Apennines: assessing the impact of water quality and habitat degradation on pool macroinvertebrates in Mediterranean rivers. Hydrobiologia 2004; 516: 313-329.

Büttner G, Kosztra B. CLC 2006 technical guidelines. European Environment Agency, Technical Report 2007.

Clapcott JE, Collier KJ, Death RG, Goodwin EO, Harding JS, Kelly D, et al. Quantifying relationships between land-use gradients and structural and functional indicators of stream ecological integrity. Freshwater Biology 2012; 57: 74-90.

Cross WF, Wallace JB, Rosemond AD, Eggert SL. Whole-system nutrient enrichment increases secondary production in a detritus-based ecosystem. Ecology 2006; 87: 1556-1565.

Croutsche JJ. Étude des relations de causalité: Utilisation des modèles d'équations structurelles (approche méthodologique). La Revue des Sciences de Gestion: Direction et Gestion 2002: 81.

Dahm V, Hering D, Nemitz D, Graf W, Schmidt-Kloiber A, Leitner P, et al. Effects of physico-chemistry, land use and hydromorphology on three riverine organism groups: a comparative analysis with monitoring data from Germany and Austria. Hydrobiologia 2013; 704: 389-415.

Downes BJ. Back to the future: little-used tools and principles of scientific inference can help disentangle effects of multiple stressors on freshwater ecosystems. Freshwater Biology 2010; 55: 60-79. 
Effenberger M, Sailer G, Townsend CR, Matthaei CD. Local disturbance history and habitat parameters influence the microdistribution of stream invertebrates. Freshwater Biology 2006; 51: 312-332.

European Council. Directive 2000/60/EC of the European Parliament and of the Council of 23 October 2000 establishing a framework for community action in the field of water policy. 2000; $72 \mathrm{p}$.

Feld CK. Response of three lotic assemblages to riparian and catchment-scale land use: implications for designing catchment monitoring programmes. Freshwater Biology 2013; 58: 715-729.

Feld CK, Hering D. Community structure or function: effects of environmental stress on benthic macroinvertebrates at different spatial scales. Freshwater Biology 2007; 52: 1380-1399.

Feld CK, Segurado P, Gutiérrez-Cánovas C. Analysing the impact of multiple stressors in aquatic biomonitoring data: A 'cookbook'with applications in R. Science of The Total Environment 2016.

Folt CL, Chen CY, Moore MV, Burnaford J. Synergism and antagonism among multiple stressors. Limnology and Oceanography 1999; 44: 864-877.

Forbes VE, Calow P, Sibly RM. The extrapolation problem and how population modeling can help. Environmental Toxicology and Chemistry 2008; 27: 1987-1994.

Frissell CA, Liss WJ, Warren CE, Hurley MD. A hierarchical framework for stream habitat classification: viewing streams in a watershed context. Environmental Management 1986; 10: 199-214.

Grace JB, Anderson TM, Olff $\mathrm{H}$, Scheiner SM. On the specification of structural equation models for ecological systems. Ecological Monographs 2010; 80: 67-87.

Hering D, Johnson RK, Kramm S, Schmutz S, Szoszkiewicz K, Verdonschot PFM. Assessment of European streams with diatoms, macrophytes, macroinvertebrates and fish: a comparative metric-based analysis of organism response to stress. Freshwater Biology 2006; 51: 17571785.

Hering D, Meier C, Rawer-Jost C, Feld CK, Biss R, Zenker A. Assessing streams in Germany with benthic invertebrates: Selection of candidate metrics. Limnologica 2004; 34: 398-415

Hill BH, Webster JR. Periphyton production in an Appalachian river. Hydrobiologia 1982; 97: 275-280.

Hill WR. Food limitation and interspecific competition in snail-dominated streams. Canadian Journal of Fisheries and Aquatic Sciences 1992; 49: 1257-1267.

Hynes HBN. The stream and its valley. Verhandlungen der Internationale Vereinigung für Theoretische und Angewandte Limnologie 1975; 19: 1-15.

Jakobowicz E. Contributions aux modèles d'équations structurelles à variables latentes. Conservatoire national des arts et metiers-CNAM, 2007.

Jin H-S, Ward GM. Life history and secondary production of Glossosoma nigrior Banks (Trichoptera: Glossosomatidae) in two Alabama streams with different geology. Hydrobiologia 2007; 575: 245-258.

King RS, Baker ME, Whigham DF, Weller DE, Jordan TE, Kazyak PF, et al. Spatial considerations for linking watershed land cover to ecological indicators in streams. Ecological Applications 2005; 15: 137-153.

Kristensen P. The DPSIR framework. National Environmental Research Institute, Denmark, 2004.

Lammert M, Allan JD. Assessing biotic integrity of streams: Effects of scale in measuring the influence of land use/cover and habitat structure on fish and macroinvertebrates. Environmental Management 1999; 23: 257-270.

Lamouroux N, Dolédec S, Gayraud S. Biological traits of stream macroinvertebrate communities: effects of microhabitat, reach, and basin filters. Journal of the North American Benthological Society 2004; 23: 449-466.

Lévêque C. Ecologie. De l'écosystème à la biosphère. Paris: Masson Sciences, Dunod, 2001.

Lorenz A, Hering D, Feld CK, Rolauffs P. A new method for assessing the impact of hydromorphological degradation on the macroinvertebrate fauna of five German stream types. Hydrobiologia 2004; 516: 107-127. 
Marzin A, Archaimbault V, Belliard J, Chauvin C, Delmas F, Pont D. Ecological assessment of running waters: Do macrophytes, macroinvertebrates, diatoms and fish show similar responses to human pressures? Ecological Indicators 2012; 23: 56-65.

Marzin A, Verdonschot PFM, Pont D. The relative influence of catchment, riparian corridor, and reach-scale anthropogenic pressures on fish and macroinvertebrate assemblages in French rivers. Hydrobiologia 2013; 704: 375-388.

Matthaei CD, Piggott JJ, Townsend CR. Multiple stressors in agricultural streams: interactions among sediment addition, nutrient enrichment and water abstraction. Journal of Applied Ecology 2010; 47: 639-649.

Minshall GW. Stream ecosystem theory : a global perspective. Journal of the North American Benthological Society 1988; 7: 263-288.

Mondy $\mathrm{CP}$, Villeneuve B, Archaimbault V, Usseglio-Polatera P. A new macroinvertebrate-based multimetric index (I2M2) to evaluate ecological quality of French wadeable streams fulfilling the WFD demands: A taxonomical and trait approach. Ecological Indicators 2012; 18: 452467.

Montgomery DR, MacDonald LH. Diagnostic approach to stream channel assessment and monitoring. Journal of the American Water Resources Association 2002; 38: 1-16.

Montier C, Le Bissonais Y, Daroussin J, King D. Cartographie de l'aléa « Erosion des sols » en France INRA, Orléans, 1998, 56 p. + cartes.

Norris RH, Webb JA, Nichols SJ, Stewardson MJ, Harrison ET. Analyzing cause and effect in environmental assessments: using weighted evidence from the literature. Freshwater Science 2012; 31: 5-21.

Novotny V. Linking pollution to water body integrity. US Environmental Protection Agency STAR Watershed Program, Boston, MA, 2004, pp. 84.

Novotny $\mathrm{V}$, Bedoya $\mathrm{D}$, Virani $\mathrm{H}$, Manolakos $\mathrm{E}$. Linking indices of biotic integrity to environmental and land use variables: multimetric clustering and predictive models. Water science and technology : a journal of the International Association on Water Pollution Research 2009; 59: 1-8.

Omernik JM. Ecoregions of the conterminous United States. Annals of the Association of American Geographers 1987; 77: 118-125.

Omernik JM. Perspectives on the nature and definition of ecological regions. Environmental Management 2004; 34: S27-S38.

Ormerod SJ, Dobson M, Hildrew AG, Townsend CR. Multiple stressors in freshwater ecosystems. Freshwater Biology 2010; 55: 1-4.

Parsons $\mathrm{M}$, Thoms MC, Norris RH. Scales of macroinvertebrate distribution in relation to the hierarchical organization of river systems. Journal of the North American Benthological Society 2003; 22: 105-122.

Parsons $\mathrm{M}$, Thoms MC, Norris RH. Using hierarchy to select scales of measurement in multiscale studies of stream macroinvertebrate assemblages. Journal of the North American Benthological Society 2004; 23: 157-170.

Paul MJ, Meyer JL. Streams in the urban landscape. Annual Review of Ecology and Systematics 2001; 32: 333-365.

Piffady J, Parent E, Souchon Y. A hierarchical generalized linear model with variable selection: studying the response of a representative fish assemblage for large European rivers in a multi-pressure context. Stochastic Environmental Research and Risk Assessment 2013; 27: 1719-1734.

Poff NL, Allan JD, Bain MB, Karr JR, Prestegaard KL, Richter BD, et al. The natural flow regime. A paradigm for river conservation and restoration. BioScience 1997; 47: 769-784.

Poff NL, Bledsoe BP, Cuhaciyan CO. Hydrologic variation with land use across the contiguous United States: geomorphic and ecological consequences for stream ecosystems. Geomorphology 2006; 79: 264-285. 
Riseng CM, Wiley MJ, Black RW, Munn MD. Impacts of agricultural land use on biological integrity: a causal analysis. Ecological Applications 2011; 21: 3128-3146.

Robinson CT, Tockner K, Ward JV. The fauna of dynamic riverine landscapes. Freshwater Biology 2002; 47: 661-677.

Roth NE, Allan JD, Erickson DL. Landscape influences on stream biotic integrity assessed at multiple spatial scales. Landscape ecology 1996; 11: 141-156.

Sanchez G. PLS path modeling with R. Trowchez Editions, Berkeley 2013.

Sponseller RA, Benfield EF, Valett HM. Relationships between land use, spatial scale and stream macroinvertebrate communities. Freshwater Biology 2001; 46: 1409-1424.

Stendera S, Adrian R, Bonada N, Cañedo-Argüelles M, Hugueny B, Januschke K, et al. Drivers and stressors of freshwater biodiversity patterns across different ecosystems and scales: a review. Hydrobiologia 2012; 696: 1-28.

Stepenuck KF, Crunkilton RL, Wang LZ. Impacts of urban landuse on macroinvertebrate communities in southeastern Wisconsin streams. Journal of the American Water Resources Association 2002; 38: 1041-1051.

Sundermann A, Gerhardt M, Kappes H, Haase P. Stressor prioritisation in riverine ecosystems: Which environmental factors shape benthic invertebrate assemblage metrics? Ecological Indicators 2013; 27: 83-96.

Tenenhaus M, Vinzi VE, Chatelin Y-M, Lauro C. PLS path modeling. Computational statistics \& data analysis 2005; 48: 159-205.

Thoms MC, Parsons ME, Foster JM. The use of multivariate statistics to elucidate patterns of floodplain sedimentation at different spatial scales. Earth Surface Processes and Landforms 2007; 32: 672-686.

Thorp JH. Metamorphosis in river ecology: from reaches to macrosystems. Freshwater Biology 2014; 59: 200-210.

Thorp JH, Thoms MC, Delong MD. The riverine ecosystem synthesis: biocomplexity in river networks across space and time. River Research and Applications 2006; 22: 123-147.

Townsend CR, Dolédec S, Norris RH, Peacock K, Arbuckle C. The influence of scale and geography on relationships between stream community composition and landscape variables: description and prediction. Freshwater Biology 2003; 48: 768-785.

Townsend CR, Uhlmann SS, Matthaei CD. Individual and combined responses of stream ecosystems to multiple stressors. Journal of Applied Ecology 2008; 45: 1810-1819.

Usseglio-Polatera P, Richoux $\mathrm{P}$, Bournaud $\mathrm{M}$, Tachet $\mathrm{H}$. A functional classification of benthic macroinvertebrates based on biological and ecological traits: application to river condition assessment and stream management. Archiv für Hydrobiologie, 2001; suppl. 139/1: 53-83.

Van Looy K, Piffady J, Tormos T, Villeneuve B, Valette L, Chandesris A and Souchon Y. Unravelling River System Impairments in Stream Networks with an Integrated Risk Approach. Environmental Management 2015; 55: 1343-1353.

Verdonschot RCM, Kail J, McKie BG, Verdonschot PFM. The role of benthic microhabitats in determining the effects of hydromorphological river restoration on macroinvertebrates. Hydrobiologia 2016; 769: 55-66.

Villeneuve B, Souchon Y, Usseglio-Polatera P, Ferréol M, Valette L. Can we predict biological condition of stream ecosystems? A multi-stressors approach linking three biological indices to physico-chemistry, hydromorphology and land use. Ecological Indicators 2015; 48: 88-98.

Vinebrooke RD, Cottingham KL, Norberg MS, Dodson SI, Maberly SC, Sommer U. Impacts of multiple stressors on biodiversity and ecosystem functioning: The role of species co-tolerance. Oikos 2004; 104: 451-457.

Vinzi VE. The contribution of PLS regression to PLS path modelling: formative measurement model and causality network in the structural model. Joint Statistical Meetings (JSM) 20082008.

Vinzi VE, Trinchera L, Amato S. PLS path modeling: From Foundations to recent developments and open issues for model assessment and improvement. In: Esposito Vinzi V, Chin W, Henseler J, 
Wang H, eds. Handbook of Partial Least Squares (PLS): Concepts, Methods and Applications. Berlin, Heidelberg, New York: Springer; 2010. pp. 47-82.

Vorosmarty, C.J., Mcintyre, P.B., Gessner, M.O., Dudgeon, D., Prusevich, A., Green, P., Glidden, S., Bunn, S.E., Sullivan, C.A., Liermann, C.R. and Davies, P.M. (2010). Global threats to human water security and river biodiversity. Nature. 467(7315): 555-561.

Wang L, Kanehl P. Influences of watershed urbanization and instream habitat on macroinvertebrates in cold water streams. Wiley Online Library, 2003.

Wang L, Robertson DM, Garrison PJ. Linkages between nutrients and assemblages of macroinvertebrates and fish in wadeable streams: implication to nutrient criteria development. Environmental management 2007; 39: 194-212.

Wasson JG, Bethemont J, Degorce JN, Dupuis B, Joliveau T. Approche écosystémique du bassin de la Loire : éléments pour l'élaboration des orientations fondamentales de gestion. Phase I : Etat initial - Problématique. Cemagref Lyon BEA/LHQ et Université de St Etienne CRENAM (CNRS 260), 1993, pp. $102+$ Atlas, 70 pl. et Annexes.

Wasson JG, Chandesris A, Pella H, Blanc L. Typology and reference conditions for surface water bodies in France: the hydro-ecoregion approach. TemaNord 2002; 566: 37-41.

Wasson JG, Villeneuve B, lital A, Murray-Bligh J, Dobiasova M, Bacikova S, et al. Large-scale relationships between basin and riparian land cover and the ecological status of European rivers. Freshwater Biology 2010; 55: 1465-1482.

Weigel BM, Wang L, Rasmussen PW, Butcher JT, Stewart PM, Simon TP, et al. Relative influence of variables at multiple spatial scales on stream macroinvertebrates in the Northern Lakes and Forest ecoregion, USA. Freshwater Biology 2003; 48: 1440-1461.

Weigelhofer $\mathrm{G}$, Welti N, Hein T. Limitations of stream restoration for nitrogen retention in agricultural headwater streams. Ecological engineering 2013; 60: 224-234.

Wold H. Soft modelling: the basic design and some extensions. Systems under indirect observation, Part II 1982: 36-37. 